\title{
Effects of substrate surface composition and deposition temperature on deposition of flat and continuous Ru thin films
}

\author{
Hirokazu CHIBA, ${ }^{* * *}$ Masaki HIRANO, ${ }^{*}$ Kazuhisa KAWANO, ${ }^{* * *}$ \\ Noriaki OSHIMA** and Hiroshi FUNAKUBO ${ }^{*, \dagger}$ \\ ${ }^{*}$ Department of Innovative and Engineered Materials, Tokyo Institute of Technology, \\ J2-43, 4259 Nagatsuta-cho, Midori-ku, Yokohama 226-8502, Japan \\ **TOSOH Corporation, 2743-1 Hayakawa, Ayase, Kanagawa 252-1123, Japan
}

$\mathrm{Ru}$ thin films were deposited by pulsed metal organic chemical vapor deposition on $\mathrm{SiO}_{2}$ (native oxide)/(001)Si, $\mathrm{HfSiON} / \mathrm{SiON} /$ $(001) \mathrm{Si}$, and $\mathrm{HfO}_{2} / \mathrm{SiON} /(001) \mathrm{Si}$ substrates at 200,210 , and $230^{\circ} \mathrm{C}$ from bis(2,4-dimethylpentadienyl)ruthenium [Ru(DMPD) $)_{2}$ $\mathrm{O}_{2}$ system. Incubation time before starting the film deposition strongly depended on the deposition temperature. Atomic force microscopy (AFM) revealed that average surface roughness, $\mathrm{Ra}$, of the $\mathrm{Ru}$ films deposited on $\mathrm{HfO}_{2} / \mathrm{SiON} /(001) \mathrm{Si}$ substrates strongly depended on the deposition temperature even though those films deposited on $\mathrm{SiO}_{2}$ (native oxide)/(001)Si substrates and $\mathrm{HfSiON} / \mathrm{SiON} /(001) \mathrm{Si}$ substrates showed small dependency on deposition temperature. In addition, it was obvious that the grain size of $\mathrm{Ru}$ films deposited on $\mathrm{HfO}_{2} / \mathrm{SiON} /(001) \mathrm{Si}$ substrate was larger than those deposited on $\mathrm{SiO}_{2}$ (native oxide)/(001)Si substrates. Minimum film thickness to obtain continuous Ru film was almost independent on the kinds of substrates and deposition temperature range from 200 to $230^{\circ} \mathrm{C}$. These results clearly show the effect of kinds of substrates and deposition temperature on flat and continuous Ru film deposition.

(C2016 The Ceramic Society of Japan. All rights reserved.

Key-words : Ruthenium, Thin films, Pulsed chemical vapor deposition, Bis(2,4-dimethylpentadienyl)ruthenium

[Received January 25, 2016; Accepted April 17, 2016]

\section{Introduction}

Ruthenium $(\mathrm{Ru})$ has been widely investigated as an electrode metal for dynamic random access memories, ${ }^{1)}$ gate metal in metal-oxide-semiconductor field-effect transistor, ${ }^{2)}$ and the seed layer material for copper interconnects due to its low resistivity of $6.7 \mu \Omega$, relatively high work function of $5.0 \mathrm{eV}$, and low diffusivity with various materials having relatively high dielectric constant, such as $\mathrm{HfO}_{2}$-based and $\mathrm{SrTiO}_{3}$-based dielectrics.

Thin film depositions of $\mathrm{Ru}$ by metal organic chemical vapor deposition (MOCVD) and atomic layer deposition have been widely investigated, ${ }^{3)-15)}$ and various kinds of $\mathrm{Ru}$ precursors, such as $\mathrm{Ru}(\mathrm{EtCp})_{2}$ and $\mathrm{RuO}_{4},{ }^{3), 4)}$ have been examined for these applications. Our groups reported ${ }^{5)}$ the effect of incubation time, the time period in which the film deposition was hardly observed at the early deposition stage, on Ru film deposition by pulsed MOCVD from (2,4-dimethylpentadienyl)(ethylcyclopentadienyl) ruthenium [Ru(DMPD)(EtCp)]- $\mathrm{O}_{2}$ system and bis(2,4-dimethylpentadienyl)ruthenium $\left[\mathrm{Ru}(\mathrm{DMPD})_{2}\right]-\mathrm{O}_{2}$ system on various substrates and concluded that the shorter incubation time results in smoother and thinner continuous films. However, details of the film characteristics deposited at different temperature were not investigated.

In this study, $\mathrm{Ru}(\mathrm{DMPD})_{2}$ was selected as a $\mathrm{Ru}$ source to deposit Ru films by pulsed MOCVD method for further investigation of the effects of substrate surface composition and deposition temperature on deposition of flat and continuous $\mathrm{Ru}$ thin films.

\footnotetext{
Corresponding author: H. Funakubo; E-mail: funakubo.h.aa@ m.titech.ac.jp

* Preface for this article: Dol http://dx.doi.org/10.2109/jcersj2.124.P6-1
}

\section{Experimental procedure}

\subsection{Film deposition}

$\mathrm{Ru}$ films were deposited by pulsed-MOCVD from $\mathrm{Ru}(\mathrm{DMPD})_{2}-\mathrm{O}_{2}$ system at 200,210 , and $230^{\circ} \mathrm{C}$ under low pressure of $130 \mathrm{~Pa} . \mathrm{O}_{2}$ gas was continuously introduced into the reactor as a reactant gas under the partial pressure of $1.3 \mathrm{~Pa}$, while, $\mathrm{Ru}(\mathrm{DMPD})_{2}$ was pulse introduced for $10 \mathrm{~s}$ with $5 \mathrm{~s}$ interval.

Substrates with amorphous top layer having various $\mathrm{Hf} / \mathrm{Si}$ ratio, $\mathrm{SiO}_{2}$ (native oxide)/(001)Si, HfSiON/SiON/(001)Si, and $\mathrm{HfO}_{2} / \mathrm{SiON} /(001) \mathrm{Si}$ substrates were used. In this study, these substrates are abbreviated as $\mathrm{SiO}_{2}$ substrate, HfSiON substrate, and $\mathrm{HfO}_{2}$ substrate, respectively.

\subsection{Film characterization}

The deposition amount was estimated by X-ray fluorescence (XRF) calibrated using standard samples. The average surface roughness, $R a$, was obtained from $5 \times 5 \mu \mathrm{m}^{2}$ square area observation using atomic force microscopy (AFM). Error bar of $R a$ value was estimated to be less than $10 \%$. A standard direct current four probe method was used for the resistivity measurement at room temperature.

\section{Results and discussion}

\subsection{Deposition behavior}

Figures 1(a)-1(c) show the deposition time dependence of deposition amount for $\mathrm{Ru}$ films deposited on various substrates at 200,210 , and $230^{\circ} \mathrm{C}$, respectively. It must be noted that the deposition time and incubation time used in the present study were the total deposition time including the time without $\mathrm{Ru}$ source supply. Therefore, actual Ru source supply time was only two-thirds of total deposition time. However, the dependence of the deposition amount on the supply time and the interval time is 

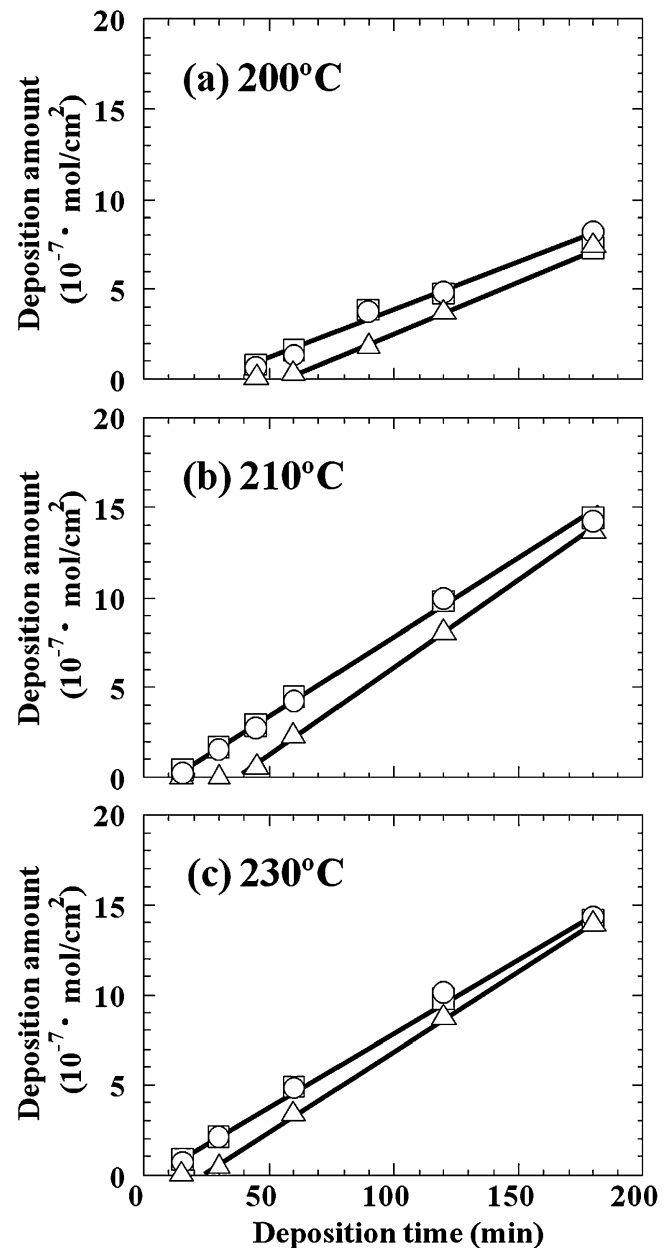

Fig. 1. Deposition time dependence of deposition amount for Ru films deposited on $(\square) \mathrm{SiO}_{2}$ (native oxide) $/(001) \mathrm{Si}\left[\mathrm{SiO}_{2}\right]$ substrates, $(\bigcirc)$ $\mathrm{HfSiON} / \mathrm{SiON} /(001) \mathrm{Si}[\mathrm{HfSiON}]$ substrates, and $(\triangle) \mathrm{HfO}_{2} / \mathrm{SiON} /$ (001) $\mathrm{Si}\left[\mathrm{HfO}_{2}\right]$ substrates at (a) $200^{\circ} \mathrm{C}$, (b) $210^{\circ} \mathrm{C}$, and (c) $230^{\circ} \mathrm{C}$, respectively. Actual Ru source supply time was only two-thirds of total deposition time, and $\mathrm{O}_{2}$ gas flow time without $\mathrm{Ru}$ source supply was the other one-third of total deposition time.

under investigation. For this reason, total deposition time is used in the present study.

Incubation time was observed for all kinds of substrate surface and deposition temperature. Incubation time estimated from Figs. 1(a)-1(c) is summarized in Fig. 2(a). Incubation time became shorter as the deposition temperature increased for all substrates. However, incubation time of the Ru films deposited on $\mathrm{HfO}_{2}$ substrates was clearly longer than those on $\mathrm{SiO}_{2}$ and HfSiON substrates for all deposition temperature range. This result shows that the kinds of substrate surface are important for incubation time as many literature mentioned. ${ }^{4), 5), 7), 8), 13)}$

Figure 2(b) summarizes the deposition rates after incubation time estimated from the data shown in Figs. 1(a)-1(c). The deposition rate after incubation time was almost independent of kinds of substrates. In the case of deposition temperature dependency, deposition rate after the incubation time increased with the deposition temperature from 200 to $210^{\circ} \mathrm{C}$, while it was almost the same at 210 and $230^{\circ} \mathrm{C}$. These two deposition temperature regions are possible to explain by the change of rate limiting steps with the temperature below and above $210^{\circ} \mathrm{C}$. For example, the deposition rate is limited by the surface reaction in the lower temperature region in which the growth rate strongly depend on
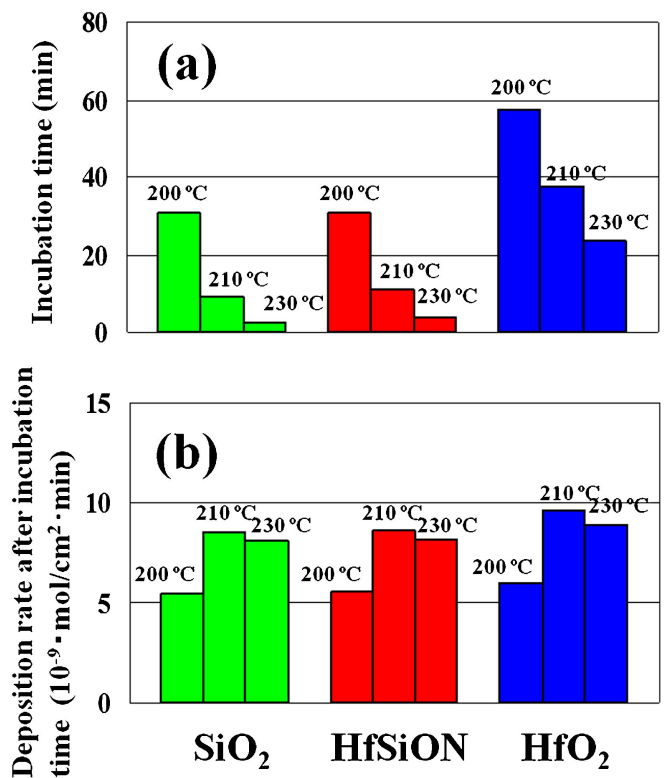

Fig. 2. (a) Incubation time and (b) deposition rate after incubation time obtained from Fig. 1 for $\mathrm{Ru}$ films deposited on $\mathrm{SiO}_{2}$ (native oxide)/ (001)Si $\left[\mathrm{SiO}_{2}\right]$ substrates, HfSiON/SiON/(001)Si [HfSiON] substrates, and $\mathrm{HfO}_{2} / \mathrm{SiON} /(001) \mathrm{Si}\left[\mathrm{HfO}_{2}\right]$ substrates at 200,210 , and $230^{\circ} \mathrm{C}$, respectively.

the deposition temperature. In contrast, the deposition rate is limited by the diffusion step of the reaction species on the reaction surface in the higher deposition temperature region, and the deposition temperature dependency of film growth rate at this region is smaller than that in surface-reaction-limited region.

\subsection{Characteristics of deposited films}

Figure 3 shows the AFM topographic images of $\mathrm{Ru}$ films deposited at 200 and $230^{\circ} \mathrm{C}$ on $\mathrm{SiO}_{2}$ and $\mathrm{HfO}_{2}$ substrates for various deposition times. Grain size of $\mathrm{Ru}$ film deposited at $230^{\circ} \mathrm{C}$ on $\mathrm{HfO}_{2}$ substrates was obviously bigger than that deposited at same temperature on $\mathrm{SiO}_{2}$ substrates and that of the films deposited at $200^{\circ} \mathrm{C}$ on both substrates.

Figure 4 summarizes the average surface roughness $(R a)$ as a function of deposition temperature for $30 \mathrm{~nm}$-thick $\mathrm{Ru}$ films deposited on $\mathrm{SiO}_{2}, \mathrm{HfSiON}$, and $\mathrm{HfO}_{2}$ substrates at 200, 210, and $230^{\circ} \mathrm{C}$, respectively. Noticeable thing is that the $R a$ value of the films deposited on $\mathrm{HfO}_{2}$ substrate was significantly increased with increasing deposition temperature, while $R a$ value of the films deposited on $\mathrm{SiO}_{2}$ and $\mathrm{HfSiON}$ substrates have a smaller temperature dependence even for the films deposited at $230^{\circ} \mathrm{C}$ at which the rate limiting step is possible to be change as suggested from the data shown in Fig. 2(b). These results indicate that $\mathrm{Ru}$ films deposited on $\mathrm{HfO}_{2}$ substrates had longer incubation time, larger grain size, and $R a$ value rather than those deposited on $\mathrm{SiO}_{2}$ and HfSiON substrates. As Shibutami et al. ${ }^{3)}$ discussed, these phenomena imply that the nuclear density at around deposition starting point on $\mathrm{HfO}_{2}$ substrate is quite lower than those on $\mathrm{SiO}_{2}$ and $\mathrm{HfSiON}$ substrates. Low nuclear density made incubation time longer and grain size larger, and large $R a$ value was due to the large grain size.

Figure 5 shows deposition amount dependency of the resistivity for $\mathrm{Ru}$ films deposited at 200,210 , and $230^{\circ} \mathrm{C}$ on $\mathrm{SiO}_{2}$, $\mathrm{HfSiON}$, and $\mathrm{HfO}_{2}$ substrates. In this figure, the deposition amount where the resistivity dramatically fell down indicates the minimum film thickness for continuous film. Almost the same 
(a) $200^{\circ} \mathrm{C}$
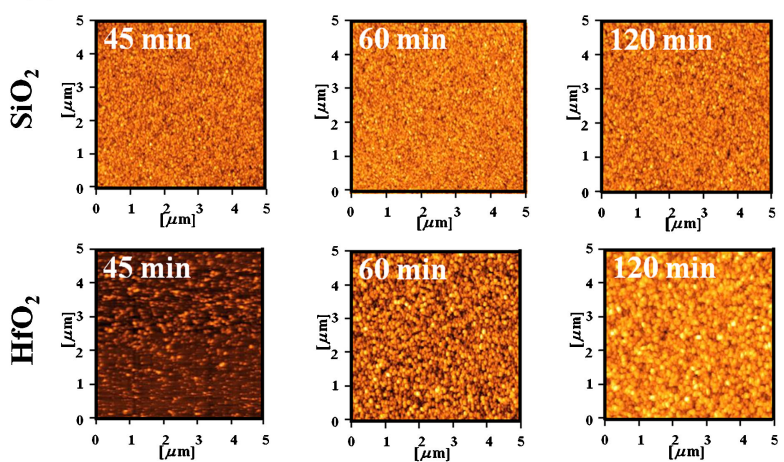

(b) $230^{\circ} \mathrm{C}$
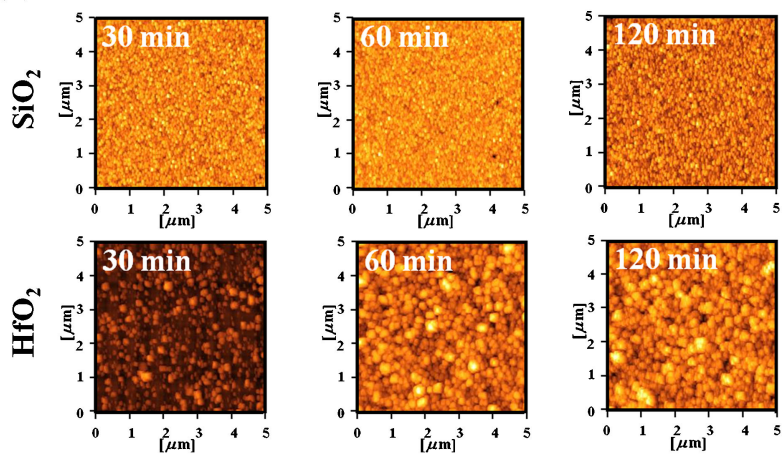

Fig. 3. AFM topological images of Ru films deposited on $\mathrm{SiO}_{2}$ (native oxide) $/(001) \mathrm{Si}\left[\mathrm{SiO}_{2}\right]$ substrates and $\mathrm{HfO}_{2} / \mathrm{SiON} /(001) \mathrm{Si}\left[\mathrm{HfO}_{2}\right]$ substrates at (a) $200^{\circ} \mathrm{C}$ and (b) $230^{\circ} \mathrm{C}$ for various deposition time.

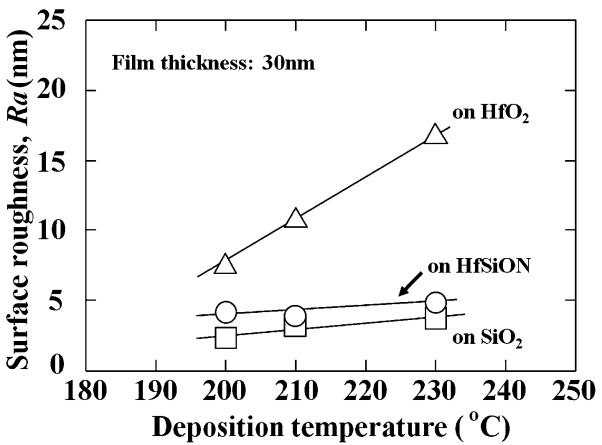

Fig. 4. Average surface roughness, $R a$, of $30 \mathrm{~nm}$-thick $\mathrm{Ru}$ films deposited on $\mathrm{SiO}_{2}$ (native oxide)/(001) $\mathrm{Si}\left[\mathrm{SiO}_{2}\right]$ substrates, $\mathrm{HfSiON} /$ $\mathrm{SiON} /(001) \mathrm{Si}[\mathrm{HfSiON}]$ substrates, and $\mathrm{HfO}_{2} / \mathrm{SiON} /(001) \mathrm{Si}\left[\mathrm{HfO}_{2}\right]$ substrates at 200,210 , and $230^{\circ} \mathrm{C}$, respectively.

tendency was observed for the resistivity of the films for all substrates and deposition temperature. This result implies that the deposition amount to obtain the continuous films on various substrates did not show a big difference within the limit of the present study even though the nuclear density is depend on the kind of the substrate surface as shown in Figs. 3 and 4.

Present results show that the deposition behavior and the deposited film character are strongly affected by the deposition temperature as well as the kinds of substrate surface.

\section{Conclusions}

Effects of kinds of substrate surface and deposition temperature on deposition of flat and continuous $\mathrm{Ru}$ thin films were investigated for the films deposited by pulsed metal organic chemical vapor deposition at 200,210 , and $230^{\circ} \mathrm{C}$ on $\mathrm{SiO}_{2}$,

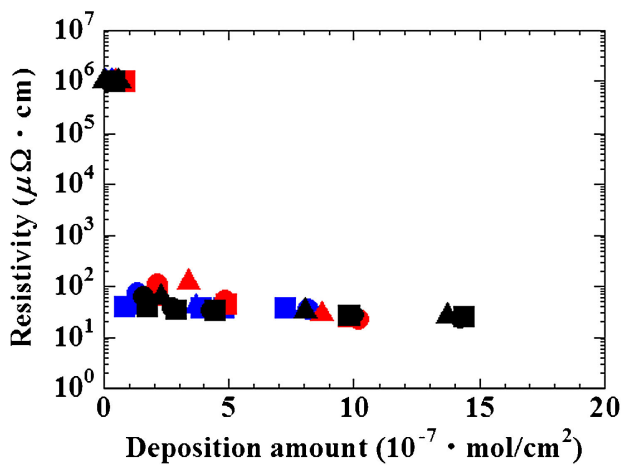

Fig. 5. Deposition amount dependency of the resistivity for Ru films deposited on $(\square) \mathrm{SiO}_{2}$ (native oxide)/(001) $\mathrm{Si}\left[\mathrm{SiO}_{2}\right]$ substrates, $(\bigcirc)$ $\mathrm{HfSiON} / \mathrm{SiON} /(001) \mathrm{Si}[\mathrm{HfSiON}]$ substrates, and $(\triangle) \mathrm{HfO}_{2} / \mathrm{SiON} /$ (001) $\mathrm{Si}\left[\mathrm{HfO}_{2}\right]$ substrates at $200^{\circ} \mathrm{C}$ (blue), $210^{\circ} \mathrm{C}$ (black), and $230^{\circ} \mathrm{C}$ (red), respectively.

$\mathrm{HfSiON}$, and $\mathrm{HfO}_{2}$ substrates from $\mathrm{Ru}(\mathrm{DMPD})_{2}-\mathrm{O}_{2}$ system. Deposition rate after the incubation time was almost independent on the kinds of substrate surface. On the other hand, the incubation time decreased with increasing deposition temperature for all kinds of substrate surface. AFM measurement showed that $R a$ value of $\mathrm{Ru}$ films deposited on $\mathrm{HfO}_{2}$ substrates were larger than those deposited on $\mathrm{SiO}_{2}$ and $\mathrm{HfSiON}$ substrates. In addition, grain size of $\mathrm{Ru}$ films deposited on $\mathrm{HfO}_{2}$ substrate was also larger than that on $\mathrm{SiO}_{2}$ films. These results indicate that the incubation time, $R a$ value, and the grain size of $\mathrm{Ru}$ films from $\mathrm{Ru}(\mathrm{DMPD})_{2}-$ $\mathrm{O}_{2}$ system depend on the kinds of substrates. These information are useful to deposit flat and continuous $\mathrm{Ru}$ thin films from $\mathrm{Ru}(\mathrm{DMPD})_{2}-\mathrm{O}_{2}$ system.

\section{References}

1) S. K. Kim, G.-J. Choi, S. Y. Lee, M. Seo, S. W. Lee, J. H. Han, H.-S. Ahn, S. Han and C. S. Hwang, Adv. Mater., 20, 14291435 (2008).

2) V. Misra, G. Lucovsky and G. Parsons, MRS Bull., 27, 212216 (2002).

3) T. Shibutami, K. Kawano, N. Oshima, S. Yokoyama and H. Funakubo, Electrochem. Solid-State Lett., 6, C117-C119 (2003).

4) J. H. Han and C. S. Hwang, ECS Trans., 58, 171-182 (2013).

5) H. Funakubo, T. Shiraishi, T. Oikawa, M. Hirano, H. Chiba and K. Kawano, J. Vac. Sci. Technol., A33, 01A149 (2015).

6) R. Methaapanon, S. M. Geyer, S. Brennan and S. F. Bent, Chem. Mater., 25, 3458-3463 (2013).

7) R. Methaapanon, S. M. Geyer, H.-B.-R. Lee and S. F. Bent, J. Mater. Chem., 22, 25154-25160 (2012).

8) M. Hirano, K. Kawano and H. Funakubo, Key Eng. Mater., 421-422, 87-90 (2010).

9) S. Y. Kang, B. S. Kim, C. S. Hwang, H. J. Kim, J. Y. Kim, K. Lee, H.-J. Lim, C.-Y. Yoo and S.-T. Kim, Jpn. J. Appl. Phys., 43, 6635-6639 (2004).

10) W.-H. Kim, S.-J. Park, J.-Y. Son and H. Kim, Nanotechnology, 19, 045302 (2008)

11) K. Kukli, M. Ritala, M. Kemell and M. Leskelä, J. Electrochem. Soc., 157, D35-D40 (2010)

12) T. Aaltonen, M. Ritala, K. Arstila, J. Keinonen and M. Leskelä, Chem. Vap. Depos., 10, 215-219 (2004).

13) S. K. Kim, J. H. Han, G. H. Kim and C. S. Hwang, Chem. Mater, 22, 2850-2856 (2010).

14) H. Li, D. B. Farmer, R. G. Gordon, Y. Lin and J. Vlassak, J. Electrochem. Soc., 154, D642-D647 (2007).

15) T. Ando, N. Nakata, K. Suzuki, T. Matsumoto and S. Ogo, Dalton Trans., 41, 1678-1682 (2012). 